\title{
Una historia del bacilo de Eberth desde Junker hasta Germanier
}

\author{
WALTER LEDERMANN D.
}

\section{A history of the Eberth bacillus from Junker to Germanier}

La historia del bacilo de Eberth no comienza con Eberth, que lo descubrió, ni con Louis, quien separó claramente la fiebre tifoidea de las "fiebres pestilenciales, pútridas, malignas, biliosas, mucosas y adinámicas" en una célebre monografía publicada en 1829: Recherches anatomiques, pathologiques et thérapeutiques sur la fièvre typhö̈de. Si bien, este francés señaló como lesión característica la ulceración de la placa de Peyer y como carácter predominante el sopor (typhus $=$ tufo, humo... y, de ahí, sopor) del período de estado, hubo otros, un siglo antes, que abonaron el camino.

Los nombres, indistintamente usados, de tifus y tifoidea vienen de muy antiguo, contribuyendo Thomas Willis a la confusión al describir la fiebre tifoidea en 1643. La aclaración comenzó con Junker en 1718, al emplear estos términos para definir afecciones específicas: Typhodes dicitur quando inflammatio erisipelacea, vel hepatis, vel ventriculi, vel uteri febrem provocat, quae anxiis, frigidis et inutilibus sudoribus conjucta est ${ }^{2}$. Esta definición cobijaba, por cierto, más de una enfermedad. El término quedaría algo más circunscrito luego que Sauvages lo precisara un poco en su Nosologia medica, en 1759, reservándolo "sólo" para algunas entidades que podrían corresponder a la tifoidea, como los typhus nervosus, hysterico-verminosus, las febris putrida, intestinalis, gastrica, mucosa y el synochus biliosus, y otras que seguramente eran las rickettsiosis o "tifus petequial", como typhus castrensis, carcerum, pestilens ${ }^{2}$.

Mientras que ingleses y franceses sostenían la identidad de los tifus intestinal (tifoidea) y petequial (exantemático y murino), los alemanes, encabezados por Hildebrand, separaron claramente ambas entidades ya en 1810. Otros predecesores de Louis fueron sus compatriotas P.A. Prost, al describir 1804 las ulceraciones intestinales en sujetos fallecidos de fiebres mucosas o adinámicas; y Petit y Serres, en 1813, al redefinir la misma entidad anátomo-clínica como "fiebre entero-mesentérica".

Last but not least, tenemos al infaltable Bretonneau de Tours, quien ya había bellamente descrito la enfermedad en 1819, acuñando el término dothiénenérite y demostrando que un ataque confería protección contra un posible nuevo episodio. Bretonneau encargó a sus discípulos divulgar su doctrina, retrasando hasta 1829 su única publicación sobre la materia y permitiendo así que Louis le ganara la mano ${ }^{4}$. Casi cien años después, en 1922, su compatriota Dubreuil-Chambardel exhumaría este precioso paper para reclamar la primacía del gran maestro, pero sería demasiado tarde.

Ya bien definida la enfermedad por Louis y otros que se fueron "subiendo al carro", como Trousseau, Andral, Chomel, Bouillaud, Jenner, Griessinger y Liebermeister, quedaba por solucionar un pequeño problema: la etiología. Los franceses Leuret de Nancy, Gendron, Piedvache y el mismo Bretonneau, alrededor de 1830, consideraban la enfermedad como específica y contagiosa, aunque la tendencia general en Francia seguía apoyando la teoría de la generación espontánea. En Inglaterra, Murchison, entre 1857 y 1862, impuso la teoría "pitogénica", expuesta en un capítulo de la segunda edición del clásico The continued fevers of Great Britain (1873) ${ }^{5}$. Murchison atribuía la enfermedad a la inhalación o ingestión accidental de sustancias pútridas emanadas de la fermentación de materias fecales y, quizás, también de otras materias orgánicas en putrefacción: febris pytogenes (del griego putresco). El célebre William Budd refutó a su colega ese mismo año, retomando las investigaciones de los franceses y admitiendo la existencia de un "principio" específico, contenido en las deposiciones de los tifosos y trasmitido a través de las ropas, alimentos, agua y hasta aire. Este "principio" sería el generador de las epidemias: "el primer caso puede ser foráneo o deberse al veneno local, que despierta como un fuego de sus cenizas, como el legado dormido de un brote antiguo semejante" ¿. ¿Aceptaría el editor de una revista moderna un lenguaje tan poético? ¡Si hasta el nombre de William Budd es literario, como que Herman Melville, el de Moby Dick, tiene una novela llamada Billy Budd!

Al mismo tiempo, en Alemania von Pettenkoffer acuñaba la Grundwassertheorie, culpando de las epidemias a cambios en las napas subterráneas, tesis que enlazaba misteriosamente con su Bodentheorie, según la cual los principios infectantes tanto del cólera como de la tifoidea era inofensivos en el agua, requiriendo un mágico contacto con la tierra para hacerse patógenos ${ }^{7}$. Todas estas teorías derivaban de diversas observaciones, bastante pintorescas, de las cuales hemos rescatado un par de perlas:

Refiere Gietl que "en 1864 volvió de Ulm a la aldea de Riedheim una joven enferma de tifoidea. Las deyecciones se vertieron en un excusado, que se limpió a las cinco semanas. Todas las personas 
ocupadas en la limpieza de aquél enfermaron de fiebre tifoidea. Las evacuaciones de los últimos enfermos se vertieron en un excusado que se limpió nueve meses después, y de nuevo enfermaron todos los sujetos ocupados en la limpieza, sujetos que no habían padecido aún la tifoidea". El mismo Gietl cuenta la trágica historia de "tres desertores que llegaron a fin del otoño a Rill (en Traunstein, Alemania) y enfermaron de tifus abdominal. Mientras estaban enfermos, estaba ocupado en la casa un carpintero, quien, después de algunos días de malestar, marchó a su casa en Scheidegg, distante dos leguas; allí fue afectado de fiebre tifoidea y, después de él, dos de sus hermanos. Otro hermano de este carpintero, que vivía a legua y media de distancia, visitaba con frecuencia a la familia y, sin enfermar él, llevó la tifoidea a casa de sus señores. El mismo muchacho cortejaba a una joven en una casa de labranza, distante una legua; esta joven enfermó de tifoidea, que desde allí propagó al valle próximo"2.

Los norteamericanos tienen una historia bastante más dramática, que involucró al más tarde famoso médico Austin Flint y que terminó en los tribunales, a la cual ya me he referido anteriormente ${ }^{8}$.

Mientras se sucedían estas pintorescas historias, el misterioso principio infectante hacía de las suyas. Durante la guerra franco-prusiana de 1870, la tifoidea se cebó en los vencedores: de los 815.000 hombres que componían el ejército de Bismarck, 74.205 enfermaron y 8.904 fallecieron. La magnitud de esta letalidad resalta si consideramos que en la mayor y decisiva batalla de Sedán, el primero de septiembre de ese año, Von Moltke perdió cerca de 9.000 soldados al cortar la retirada de Marshall Mac Mahon: en otras palabras, el general francés fue tan efectivo como el bacilo de Eberth ("no hubo diferencia significativa") ${ }^{9}$. Al otro lado del océano, la tifoidea se vengó en los triunfadores de la Guerra de Secesión, matando 27.056 de los 431.237 soldados de la Unión. Y en la guerra con los boers, en el Transvaal, los ingleses perdieron tantos hombres por la tifoidea como por heridas de guerra $(8.000$ versus 8.600$)^{10}$.

Entonces, en una lucha que culminará en 1880 , dos científicos alemanes compiten con sendos bacilos para explicar la etiología de la tifoidea y poner término a todas las teorías: el patólogo Carl Joseph Eberth (1835-1926) y el inefable Ferdinand Klebs. El bacillus typhosus Klebs era largo, flaquito y solía formar esporas terminales: obviamente no era una Enterobacteriaceae, pero le dio pelea por varios años al legítimo bacillus typhosus Eberth, más corto, grueso y no esporulado, aunque a veces presentara formas cuasi esféricas. Luego de 23 autopsias, pudo Eberth recuperar el mismo bacilo del bazo en 12 casos y de los ganglios mesentéricos en $6^{11}$ ). Al año siguiente, tuvo menos suerte en una segunda serie de 17 autopsias, encontrando sólo 6 positivas, pero no encontró bacilos en ninguna de otras 26 , correspondientes a patologías distintas de la tifoidea ${ }^{12}$. También en 1881 Koch vio el bacilo, y "hasta lo fotografió" (¿?), en el riñón, bazo e hígado de otro paciente fallecido. Finalmente, utilizando los nuevos medios de cultivo sólidos desarrollados por Koch, Gaffky logró cultivar el bacilo en 1884 .

Detengámonos un poco en este último y olvidado investigador Georg Theodor August Gaffky (1850-1918) fue un bacteriólogo alemán que, pese a sus numerosos aportes a la bacteriología, vio su nombre conservado sólo en relación a una bacteria insignificante, no patógena, la Gaffkya tetragena que, para colmo, ahora se trasladó al género Aerococcus $^{13}$, de modo que, de Gaffky, nada. También se le recuerda en relación a su escala pronóstica para la tuberculosis, basada en el recuento de bacilos en el esputo ${ }^{14}$. Gaffky sembró su muestra en la superficie de una papa: al no ver desarrollo microbiano, estuvo a punto de botarla, pero antes decidió echarle una miradita al microscopio, descubriendo que había abundante crecimiento del bacilo.

Entonces cometió Gaffy un par de errores. Primero, al traspasar a papa a $37^{\circ} \mathrm{C}$, encontró sólo esporas del bacilo y así las describió: como entonces no existía la tinción de Gram, no advirtió que era una grosera contaminación con lo que hoy llamamos Bacillus. Luego, intentando cumplir con los postulados de su maestro, inoculó el bacilo (el verdadero, no el contaminante) en unos sesenta animales y pájaros distintos, sin lograr reproducir una enfermedad que es exclusivamente humana. Tampoco fue capaz de aislar la bacteria de sangre o de deposiciones, restringiéndose sus éxitos a hallazgos de autopsia. Y aunque "discutió todo el problema de la etiología, modo de infección y profilaxis, de una manera que ha hecho de esa publicación un clásico de la literatura bacteriológica"15, el bacilo llevó el nombre de Eberth, nombre que ha resistido hasta ahora todos los cambios que los porfiados taxonomistas han intentado con la bacteria que seguimos llamando indistintamente Salmonella typhi o "bacilo de Eberth".

Aunque la identidad del bacilo estaba clara, existían problemas prácticos para su aislamiento desde las deposiciones, donde predominaba el colibacilo. Dos adelantos importantes iban a facilitar el proceso: la seroaglutinación de Widal, en 1896, y el método de hemocultivo de Schotmüller, en 1900.

Georges Fernand Isidore Widal (1862- 1929) fue un distinguido médico francés que infectólogos y microbiólogos recordamos por la reacción de seroaglutinación, pero en vida se le reconoció más mérito por su descripción de la icteroanemia hemolítica o síndrome de Widal, "enfermedad caracterizada por el desarrollo de ictericia y anemia, con crecimiento esplénico, urobilinuria, y una hemolisis asociada con fragilidad de los corpúsculos rojos de la sangre"16. El test de aglutinación de Widal permitió a Archard y Bessaude enunciar la existencia de un bacilo paratífico en 1896, al tener una reacción negativa en un franco tifoso.

Pese a algunos detractores, la teoría del contagio a través del agua contaminada por deposiciones terminaría por imponerse. Una larga sucesión de grandes brotes y epidemias, en relación a fallas de los filtros utilizados en los suministros de agua municipales, iba acumulando evidencia. En 1882, se 
desató una epidemia en los cuarteles militares de Auxerre, porque una jovencita tifosa había defecado muy cerca de las fuentes de agua, como se comprobó Dionis inyectando anilina en el pozo negro ${ }^{17}$. En 1890 un tifoso llegado de Paris contaminó en pocas horas las aguas de un balneario en Calvados, hecho investigado y demostrado por Brouardel y Thoinot ${ }^{17}$. Y en Clermont- Ferrand y en Altona y etc, etc. Pero el más célebre, por el proceso judicial en que derivó, fue el de Gelsenkirchen ${ }^{18}$, que causó más de tres mil casos, con una letalidad de ocho por ciento, al cual también me he referido anteriormente ${ }^{8}$.

Entre tanto y siempre a principios del siglo XX, las investigaciones de Schotmüller y luego de Bryon y Kayser iniciaron la separación de los tres agentes de las fiebres tíficas, separando el bacilo de Eberth de las Salmonella paratyphi A y paratyphi B. Luego la Eberthella, con los sucesivos cambios de typosa a typhi, se incoporaría, con la misma sucesión en el segundo término, al género Salmonella. Actualmente ha perdido su carácter de especie, siendo una de las infinitas variedades serológicas de la Salmonella enterica, ex-Salmonella cholerae-suis.

En 1896, comenzó Wright los primeros ensayos en humanos con una vacuna tífica muerta ${ }^{19}$, que se inyectaba por vía subcutánea y que tuvo su espaldarazo al inmunizar al ejército francés en la primera guerra mundial. Una larga serie de ensayos intentaría mejorar la vacuna: la de Vincent ("al éter"), la de Durand o thiovaccin, la vacuna antitóxica de Grasset, la variante de Kauffmann, la alcoholada de Félix, todas inyectables; y la bilivacuna oral de Besredka, basada en su concepción de la inmunidad local $^{20}$, seguida por la enterovacuna de Lumière y Chevrotier, desarrollada a partir de los ensayos de Courmont y Rochaix en $1912^{21}$. La vacuna de Wright, con cepa muerta por calor-fenol persistió hasta nuestra época, con mejoras técnicas que no lograron atenuar suficientemente las grandes reacciones locales y generales. Numerosos fueron los intentos por resucitar una vacuna oral, en especial los que usaron cepas vivas, no virulentas, como las cepas estreptomicina-dependientes de la década de 1960, para terminar con el desastre de Evans, que murió al ensayar su propio producto no suficientemente atenuado. Por último, ya en los años ochenta, Germanier ${ }^{22}$ desarrolló una mutante incapaz de metabolizar la galactosa, la cepa Ty 21a, vacuna que debutó con cierto éxito en Alejandría ${ }^{23}$ para luego desdibujarse en Chile ${ }^{24,25}$ y otros países del tercer mundo ${ }^{26}$. En forma paralela, los trabajos con el antígeno de superficie Vi han tenido marcadas vicisitudes, sin llegar a obtener un producto plenamente convincente ${ }^{27}$.

Si bien los brotes epidémicos por consumo de agua o alimentos contaminados continuaron salpicando la historia del bacilo de Eberth, la falta de una buena vacuna fue en parte soslayada por la mejoría en las condiciones higiénicas y por el descubrimiento del cloranfenicol en $1947^{28}$, medicamento mágico que asestó a la tifoidea un golpe maestro ${ }^{29}$. El bacilo tífico demostró desde entonces ser débil frente a los antibióticos y - salvo la epidemia por una cepa resistente en México ${ }^{30}$ nunca ha sido capaz de generar una resistencia antibiótica digna de considerar.

Bondadosa, después de todo, la Salmonella enterica ( ex-cholerae-suis) var Typhi, cuyo nombre ya no recuerda a Eberth. ¿Y por qué a Salmon? Recurriendo a mi antigua edición de Bergey's ${ }^{31}$, manual considerado la "biblia" de la bacteriología, encuentro el nombre mencionado por primera vez en 1930, en relación a un par de publicaciones en el volumen 29 del Journal of Hygiene, que no me he molestado en buscar, la primera de Warren, página 416, y la segunda de White, página 443. Al denominar Salmonella a este género que definiera Lignières en 1900, se quiso honrar la memoria del doctor Daniel Elmer Salmon (1850-1914), un patólogo y bacteriólogo norteamericano, de quien, tras exhaustiva búsqueda a través de los libros clásicos de microbiología y de infectología, sólo he encontrado en la misma edición de Bergey's una breve referencia a dos publicaciones suyas, ambas en relación a la actual Salmonella enterica ser Cholerae-suis, considerada tradicionalmente especie tipo del género Salmonella. Estas publicaciones corresponden a sendos -e inaccesibles- reportes anuales de una dependencia del Departamento de Agricultura de EE.UU.: la primera sobre el Bacterium of swine plague (US Dept Agr Bur Ann Ind Ann Rept 1885, p. 212) y la segunda acerca del Bacterium of the hog cholera (ibid 1886, p.20).

Especulando un poco, consideremos las posiciones relativas de EE.UU. y de Alemania en el concierto mundial en 1930: mientras el primero surgía triunfador, como una fuerza renovadora en todos los campos, la nación europea vivía los oscuros días de su derrotada postguerra. En este escenario, poca fuerza tendría el mejor derecho de los germanos Eberth, Gaffky, Klebs o Schottmülleri para verse eternizados en el género a cuyo mejor conocimiento tanto aportaron, permitiendo a los discípulos de Salmon imponer el nombre de quien estudió uno de entre los casi dos mil serotipos de una especie zoonótica.

Recordando lo que ocurrió al momento de bautizar nuestro continente, en relación a las magnitudes de los descubrimientos de Colón y de Vespucio, y evaluando la desigual importancia que para la salud mundial tienen la Eberthella typhosa y el Bacterium cholerae-suis, podríamos decir - sin pretender poner en duda los méritos que sin duda tuvo este investigador y quizás incurriendo en una injustificada irreverencia -que Salmon "se hizo la América" con su bacilo porcino.

\section{Bibliografía}

1.- Louis P C A. Recherches anatomique, pathogenique et thérapeutique sur la maladie connue sous les noms de gastro-entérite et des outres. Mason et fils, Paris 1841.

2.- Eulenburg A. Diccionario enciclopédico de medicina y cirugía prácticas. Saenz de Jubera Hermanos, Madrid 1890; XII: 496.

3.- Prost P A. Médecine éclairée pour l'observation et l'ouverture des corps. Paris 1804, vol II. 
4.- Bretonneau de Tours. Etude de la fièvre entero mesentherique (dothiénentérite). Arch Gen Méd 1829; 21: 57-67.

5.- Murchison C. A treatise on the continued fevers of Great Britain, 3d edition, London 1884.

6.- Budd W. A contagious principle on enteric fevers. Br Med J 1859; ii: 4-28.

7.- Evans A. Two errors in enteric epidemiology : the stories of Austin Flint and Max von Pettenkofer. Rev Infect Dis 1985; 7 (3): 434-40.

8.- Ledermann W. El bacilo de Eberth lleva los médicos al tribunal. Rev Chil Infect 1992; 9 (3): 189-92.

9.- Bonner A. Battle of Sedan. Collier's Encyclopedia, Crowell Collier and Mc Millan Inc, USA 1967; 20: 563.

10.- Pilod M, Coumel H. Fiévres typhoïde et paratyphoïdes. En: Encyclopedie des Maladies Infectieuses, Paris 1949; 8019 A: 1-2.

11.- Eberth C J. Bacillus typhosus. Virchow Arch 1880; 81 (I): 58.

12.- Eberth C J. Bacillus typhosus. Virchow Arch 1881; 83 (I): 486

13.- Dorland's Illustrated Medical Dictionary. W.B. Saunders Co., 28th edition, Phi 1994; pp 671.

14.- Dorland's Illustrated Medical Dictionary. W.B. Saunders Co., 28th edition, Phi 1994; pp 1488.

15.- Bulloch W. Bacillus typhosus. History. In : A system of bacteriology in relation to medicine. His Majesty's Stationary Office, London 1929; IV: 15-17.

16.- Dorland's Illustrated Medical Dictionary. 28th edition, WB Saunders Co., Phi 1994; pp 816, 1844.

17.- Pilod M, Coumel H. Fiévres typhoïde et paratyphoïdes. Encyclopédie des Maladies infectieuses, Paris 1949; 8019A: 6.

18.- Howard-Jones N. Gelsenkirchen typhoid epidemic of 1901. Robert Koch and the dead hand of Max von Pettenkofer. Br Med J 1973; 1: 103-105.

19.- Wright A E. Typhoid vaccine. Lancet 1896; ii: 807-12.

20.- Harvey D. Bacillus typhosus. Immunization and therapy. En: A system of bacteriology in relation to medicine. His Majesty's Stationary Office, London
1929; IV: 50-64.

21.- Pilod M, Coumel H. Fiévres typhoïde et paratyphoïdes. Encyclopédie des Maladies infectieuses. Paris 1949; 8023A: $1-5$.

22.- Germanier R, Furer E. isolation and characterization of Gal e mutant Ty 21 of Salmonella typhi : a candidate strain for a live oral typhoid vaccine. J Infect Dis 1975; 131: 553-8.

23.- Wahdan M H, Serie C H, Cerisier Y, Sallam S, Germanier R: A controlled field frial of live Salmonella typhi strain Ty-21a oral vaccine against typhoid: threeyear results. J Infect Dis 1982; 145: 292-5.

24.- Levine M M, Ferreccio C, Black R E, Germanier R. Chilean Typhoid Committee: Large-scale field trial of Ty21a live oral typhoid vaccine in enteric-coated capsule formulation. Lancet 1987; 1: 1049-52.

25.- Levine M M, Ferreccio C, Cruz S, Ortiz E. Comparison of enteric-coated capsules and liquid formulation of Ty21a typhoid vaccine in randomised controlled field trial. Lancet 1990; 336: 891-4.

26.- Simanjuntak C H, Paleologo F P, Punjabi N H et al. Oral immunisation against typhoid fever in Indonesia with Ty21a vaccine. Lancet 1991; 338: 1055-9.

27.- Klugman K P, Koornhof H J, Robbins J B, Le Cam N N. Immunogenicity, efficacy and serological correlate of protection of Salmonella typhi Vi capsular polysaccharide vaccine three years after immunization. Vaccine 1996; 14: 435-8.

28.- Ehrlich J, Bartz Q R, Smith R M et al. Chloromycetin, a new antibiotic from a soil actinomycete. Science 1947; 106: 417-9.

29.- Woodward T E, Smadel J E,Ley H L et al. Preliminary report on the beneficial effect of chloromycetin in the treatment of typhoid fever. Ann Intern Med 1948; 29: $131-4$

30.- Vásquez V, Claderón E, Rodríguez R S. Chloramphenicol resistant strains of Salmonella typhosa. N Engl J Med 1972; 286: 1220.

31.- Breed R S, Murray E G, Smith N R. Bergey's Manual of Determinative Bacteriology. 7th ed. The Wilkins \& Wilkins Co, Baltimore, USA, 1957; p 370. 